\title{
THE IMPACT OF THE PANDEMIC LOCKDOWN ON AIR POLLUTION, HEALTH AND ECONOMIC GROWTH: SYSTEM DYNAMICS ANALYSIS
}

10.36740/WLek202011102

\author{
Vladyslav A. Smiianov' ', Oleksii V. Lyulyov' ', Tetyana V. Pimonenko', Tetyana A. Andrushchenko², Serhii Sova', \\ Natalia V. Grechkovskaya ${ }^{3}$ \\ 'SUMY STATE UNIVERSITY, SUMY, UKRAINE \\ 2STATE INSTITUTION“KUNDIIEV INSTITUTE OF OCCUPATIONAL HEALTH OF THE NATIONAL ACADEMY OF MEDICAL SCIENCES OF UKRAINE, KYIV, UKRAINE \\ ${ }^{3}$ BOGOMOLETS NATIONAL MEDICAL UNIVERSITY, KYIV, UKRAINE
}

\begin{abstract}
The aim of the paper is checking the hypothesis on the linking between consequences of pandemic lockdown and air pollution, public health, and economic growth. Materials and methods: for prediction and modelling of the pandemic lockdown's impact on the air pollution, health, and economic growth with the system dynamics analysis and software Vensim; for the analysis, the authors used the methods as follows: bibliometric analysis with Scopus Tools Analysis and software VOSviewer.

Results: The findings confirmed that the current rate of infected from growing disease was $11 \%$. If quarantine continues the rate of infected from the growing disease will be $15 \%$. If the quarantine cancels the rate of infected from the growing disease will be $5 \%$, and the declining of GDP increment will be higher, than in scenario with quarantine. Conclusions: The findings confirmed the hypothesis that lockdown has the negative impact on the economic, social, and ecological growth of the country. At the same time, in the case, if the government cancel the quarantine, the declining of GDP increment will be higher, and the rate of infected from the growing disease will be the highest - $15 \%$. In this case, the government should provide the quarantine regime and strengthen the control of the compliance.
\end{abstract}

KEY WORDS: economic growth, health economics, pandemic, public health

Wiad Lek. 2020;73(11):2332-2338

\section{INTRODUCTION}

The pandemic lockdowns have an impact in all spheres from public health to economic and ecological development of the country. The scientists proved that lockdown is the most effective way to stop the extending and penetration of virus among society. Form the other side lockdown leads to the collisions between the economic, the social, and the ecological spheres. The findings of a retrospective analysis of consequences from pandemic confirmed the existence of the direct (public health) and indirect effects (economic, social, and ecological development of the country). Thus, considering the findings in the paper [1] in the pandemic periods (on the United Kingdom examples 1270-2019 years) the death rate increased, and GDP per capita decreased which limit the financing into the healthcare sector in the country. Besides, the scientists concluded that the highest level of unemployment was during the lockdown under the Great Pandemic (1870-1875) and the Russian flu [1].

The new wave of coronavirus disturbs the whole world and has provoked the vulnerable and imbalance the social and economic development. The findings of bibliometric analysis confirmed that scientists around the world are trying to analyse of the predictors of the pandemic, predict the consequences and foresight the ways to the recovering after lockdowns. Only the 9 months of the 2020 year the numbers of publication on investigation the pandemic from the medical, economic, and social points of views in the scientific Journal which indexed by Scopus has increased from 300-400 publications in 2019 to 20000 21000 papers. The visualising co-occurrence map allowed concluding that scientists analysed the pandemic under several scientific directions (Fig. 1).

The findings allowed allocating the five scientific directions on the investigation of the pandemic. Thus, the first biggest cluster (red colour) focused on the analysis of the pandemic in relation with public health and socio-economic development issues (social isolation, the income of the society, trust, and awareness). The second cluster (green) focused on the immunology and virology aspects of the pandemic. The third cluster analysed the factors and determinants, which influenced on the pandemic consequences spreading and extending. In the paper [2] the scientists allocated the age as the main factor which influenced the virus penetrating. The fourth cluster (yellow) showed that the scientists analysed the linking between pandemic and air pollutions, climate change, health risks etc.

Noted, that most citable paper (4231 numbers) was published in 2020 in JAMA - Journal of the American Medical Association (Q1) by the Chinese scientists [3]. They presented the clinical findings of the COVID on examples of Wuhan (Chine). 


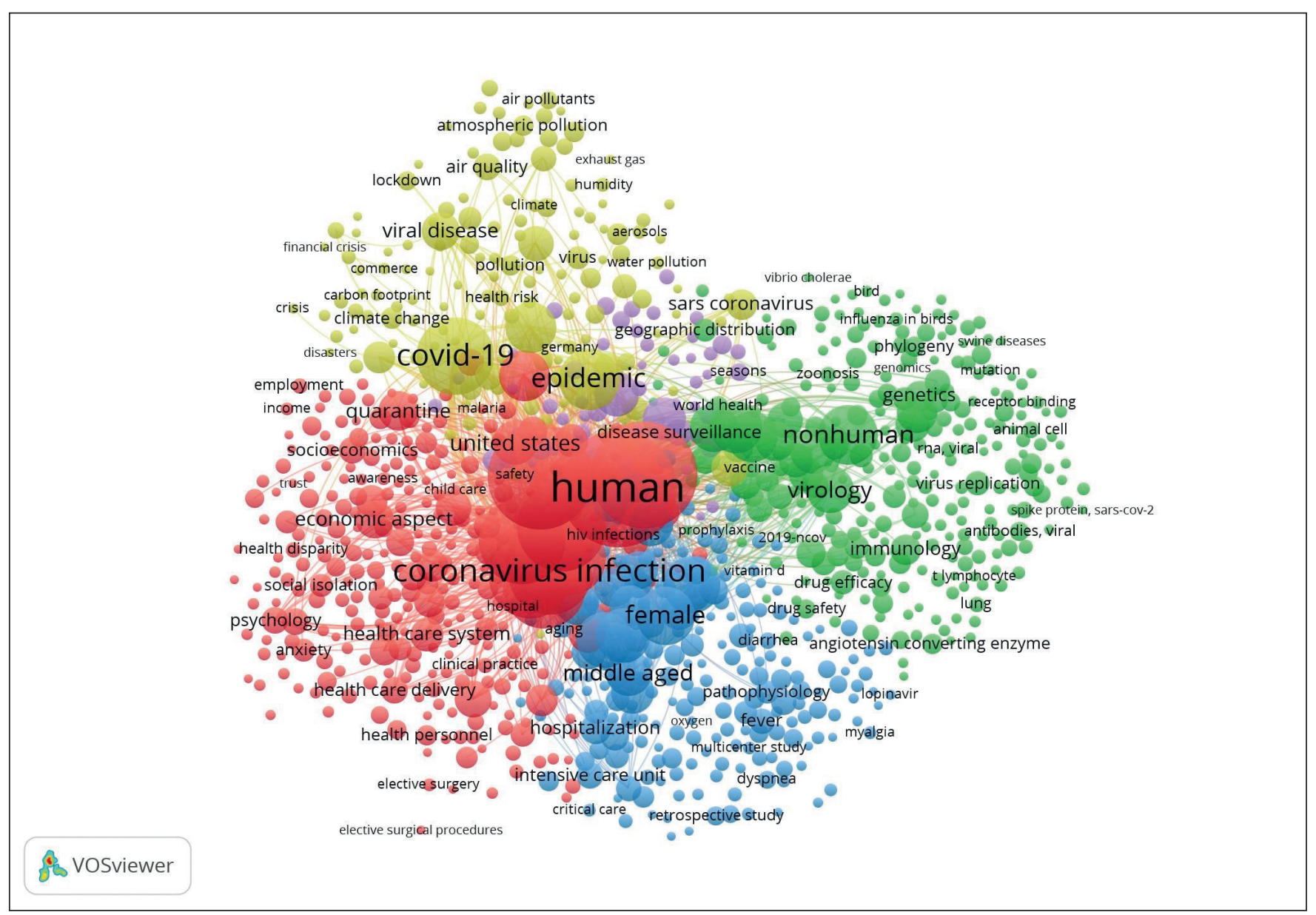

Fig. 1. The visualising map of bibliometric analysis of the papers which focused on the investigation of linking between pandemic, air pollution, public health, and economic growth

Source: developed by the authors used VOSviewer and Scopus.

The results of the bibliometric analysis confirmed the increasing interest of the scientists to analyse of the pandemic issues not only from the medical issues [1-3] but also from the social, ecological and economic points of views [4-13]. Besides the vulnerableness of the world under the coronavirus requires the developing of the effective instruments to overcome the recession after the lockdowns. In this case, it is necessary to understand what sphere will be suffered most of all. In order, it requires identifying and empirical justify the linking between the consequences of pandemic lockdown and main economic, social, and ecological parameters.

\section{THE AIM}

The checking the hypothesis on the linking between consequences of pandemic lockdown and air pollution, public health, and economic growth.

\section{MATERIALS AND METHODS}

In the economic theory, the scientists empirical justified the process which relates to the correlation of the economic growth and its social development which measured by the efficiency of supporting and improving the quality of public health. Considering the EKC hypothesis, the economic growth is the instrument to achieve the goals on increasing of quality of public health and protecting of the environment. In this case, the developing countries should provide the policy on economic growth which lead to the achievement of the socioecological and economic goals. At the same time, the isolated government policy-oriented only on environmental protection or only on the social growth limit the economic growth [14]. The graphical interpretation of this hypothesis could be shown as an inverted U-shaped curve (Fig. 2)

In the mathematical expression, the EKC hypothesis could be presented as a function:

$\mathrm{E}=\mathrm{F}\left(\mathrm{Y}, \mathrm{Y}^{2}, \mathrm{Z}\right)$

where E - environmental pollution (per capita GHG emissions), Y - output (per capita GDP), Z - the explanatory variables.

This function derived from the neoclassical theory of economic growth. The Cobb-Douglas production function was the first among all functions. The types of Cobb-Doug- 


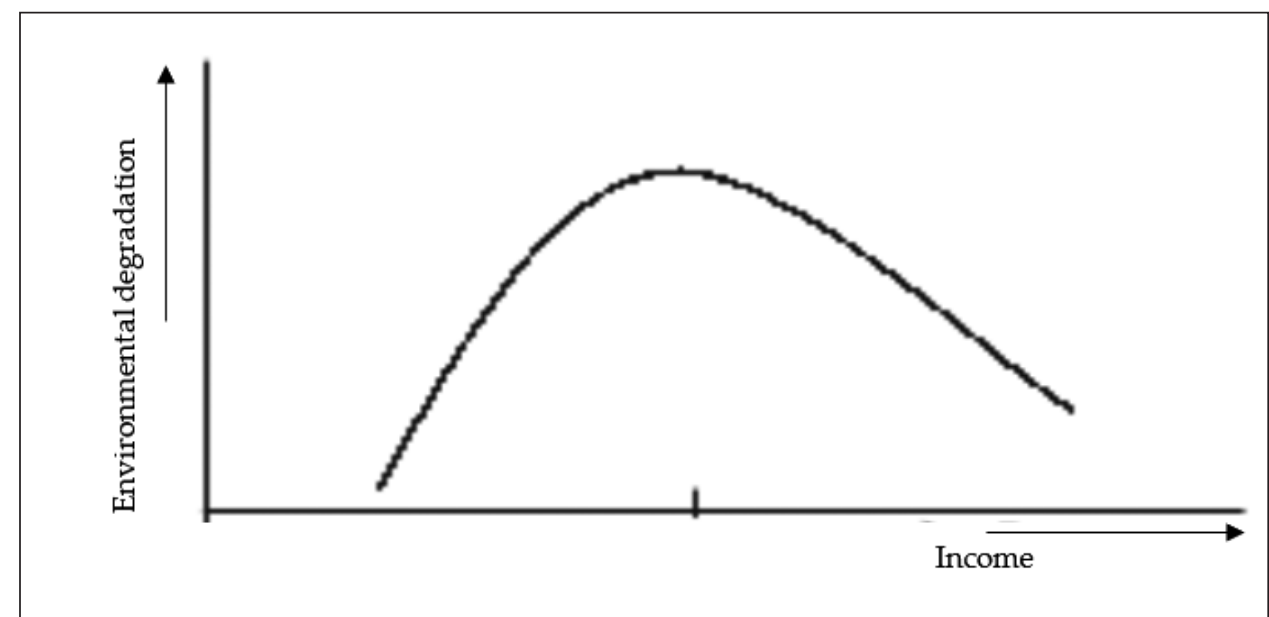

Fig. 2. Environmental Kuznets Curve.

las production function use for defining the production volume as the multiplication of production volume and capital. The general function which was developed by the American scientists' Cobb and Douglas in 1928 [15] using the data of economic development of the USA for 18991922 , showed in formula 2 :

$\mathrm{Q}=\mathrm{AL}^{\alpha} \mathrm{K}^{\beta}$

where Q - total production (GDP); L - labour costs; K - capital; $\alpha$ i $\beta$ - coefficients of elasticity, respectively, of capital and labour; A - coefficients of proportionality and scaling, which allows comparing the volume of production from the different time.

At the same time, the global pandemic causes the internal and external shocks through run-on of quarantine which influences on sustainable development of the country. Thus, in the paper [17] the scientists developed the theory on the relations and relationships COVID-19 contagion, government expenditure to the healthcare management and economic indicators of the country development. The authors [17] highlighted the necessity of using the methods of the system dynamics analysis for the justification of the effects of interrelated factors. The similar conclusion was received by the authors in the paper [18]. The authors used the system dynamics approach for modelling the impact of health factors on the economic growth and software VENSIM justified the positive statistically significant impact the social development indicators on the economic growth of the country.

Thus, in the framework of this investigation, the system dynamics analysis was the methodological base for the analysis of the impact of the pandemic lockdown on air pollution, health, and economic growth. It allows considering at the same time, the multiple intersections of different variables of the above concepts in the systems of equations. Besides, the main advantage of this approach is considering of dynamic nature of the process of change which is in the country because of the introduction of quarantine restrictions during COVID 19.
System dynamics analysis include the stage as follows as [19]: developing of the hypothesis of the investigation; identification of the structure and system's modules; causal relationships between them and feedback mechanisms; developing of systems of dynamic equations which emphasis of the processes of change in the social, ecological and economic indicators of the country development; forecasting of social, ecological and economic consequences due to different scenarios of quarantine restrictions using the methods of the system dynamic simulation modelling in Vensim; assessment of the efficiency of the government economic policy during the pandemic.

\section{RESULTS AND DISCUSSION}

At the first stage of System Dynamics Analysis, the system of the dynamic equations could be presented as a variation of relations between variables in the subsequent chain reactions:

(1) GDP $\rightarrow$ quality of life $\rightarrow$ population $\rightarrow$ the number of employed (able-bodied) population; $\rightarrow$ GDP;

(2) GDP $\rightarrow$ green investments on declining of air pollution $\rightarrow$ quality of environment $\rightarrow$ investment in the fixed assets $\rightarrow$ GDP;

(3) GDP $\rightarrow$ investments in the health care system $\rightarrow$ quality of medical care for patients with COVID $19 \rightarrow \rightarrow$ rate of death $\rightarrow$ number of employed (able-bodied) population $\rightarrow$ GDP.

The identified chain interaction parameters allowed developed the casual diagram impact of the pandemic lockdown on air pollution, health, and economic growth (Fig. 3).

The system of the dynamic equations allowed emphasising of the processes of change in the social, ecological, and economic indicators of the country development. The main parameters of the analysis were shown in Table 1.

According to the World Bank Data, economic losses due to a pandemic can be divided into three main categories: about $12 \%$ - related to mortality, $28 \%$ - due to lack of workers, to $60 \%$-from changes in economic and social behaviour [21]. More recently, the scientific papers and 


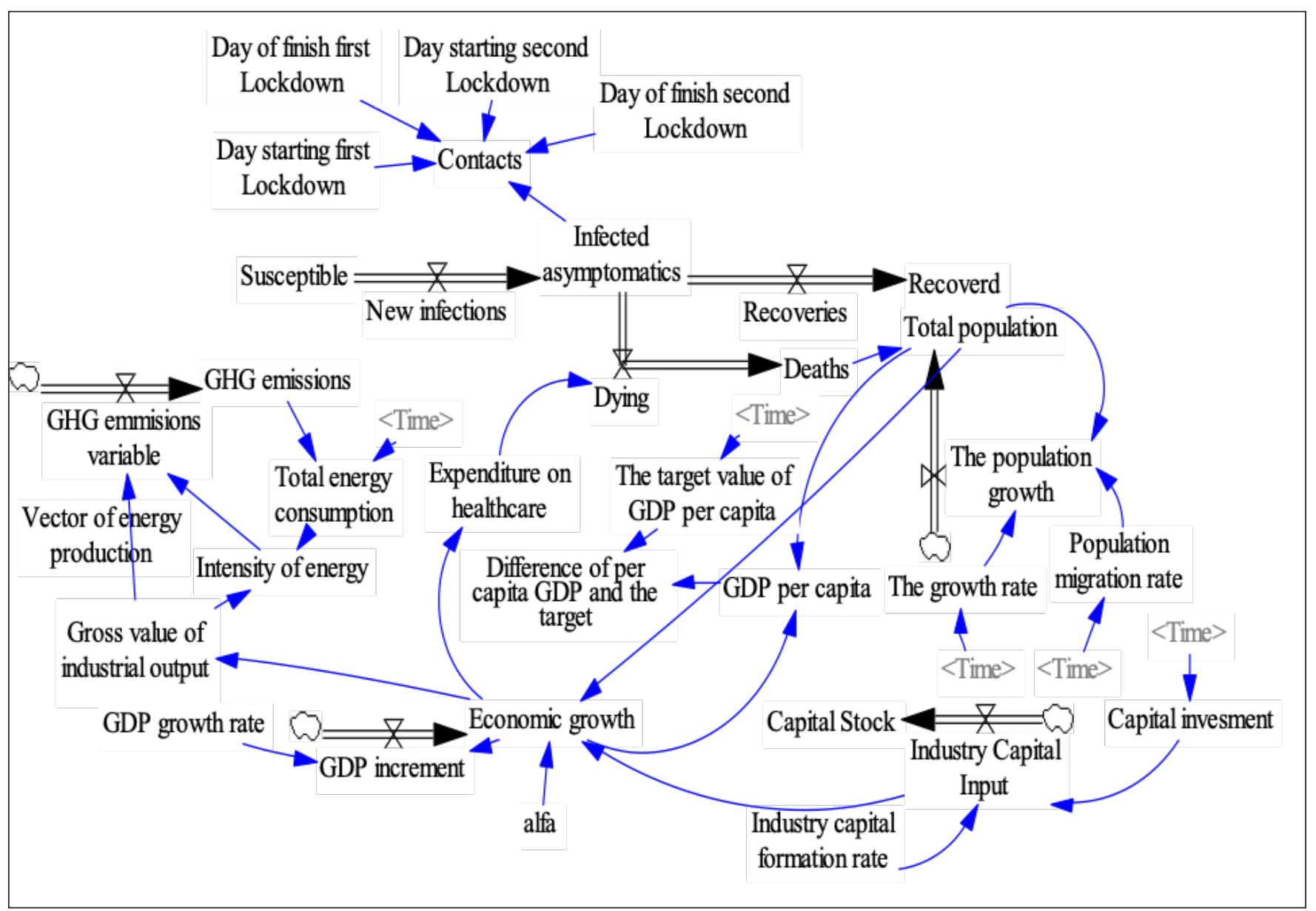

Fig. 3. System causalities of the health, ecology, and economic systems.

Note: $\rightarrow-$ casual impact of the indicators; $\Rightarrow-$ is a rate variable, a cloud represent a source the starting point of the rate variable.

Table 1. Mainly equations in system dynamic model

\begin{tabular}{|c|c|c|}
\hline Factors & Specific Parameters & Equation \\
\hline \multirow{3}{*}{ Environmental factor } & GHG emissions & $=\mathrm{GDP} \times \mathrm{Intensity}$ of energy $\mathrm{x}$ Vector of Energy Production \\
\hline & Intensity of energy & $=$ Total energy consumption/Gross value of industrial output \\
\hline & Vector of Energy Production & $=$ GHG emissions $/$ Total energy consumption \\
\hline \multirow{7}{*}{$\begin{array}{l}\text { Health and population } \\
\text { factor }\end{array}$} & Susceptible & $=$ Total population - Initial infected \\
\hline & Infected asymptomatic & $=$ Susceptible $\mathrm{x}$ New infections \\
\hline & Recovered & $=$ Infected asymptomatic $\mathrm{x}$ Recoveries \\
\hline & Death & $=$ Infected asymptomatic $\times$ Dying \\
\hline & Expenditure on healthcare & $=\% \mathrm{GDP}$ \\
\hline & The population growth & $=$ The growth rate $x$ Total population \\
\hline & Total population & $=$ The initial population-Death \\
\hline \multirow{6}{*}{ Economic factor } & Economic growth & $=($ Total population^^alfa $) \times($ Industry capital input $\wedge(1-a l f a))$ \\
\hline & $\begin{array}{l}\text { The difference of per capita GDP and the } \\
\text { target }\end{array}$ & = GDP per capita-The target value of GDP per capita \\
\hline & The target value of GDP per capita & $\begin{array}{l}=\text { providing the annual growing of GDP in average not less than } \\
4 \% \text { for } 2017-2020 \text { years, } 6 \%-\text { for } 2021-2025 \text { years and } 7 \%-\text { for } \\
2026-2030 \text { years. }\end{array}$ \\
\hline & GDP per capita & $=\mathrm{GDP} /$ Total population \\
\hline & GDP increment & $=$ GDP growth rate $x$ GDP \\
\hline & Industry capital input & $=$ Industry capital formation rate $\times$ Capital Investment \\
\hline
\end{tabular}




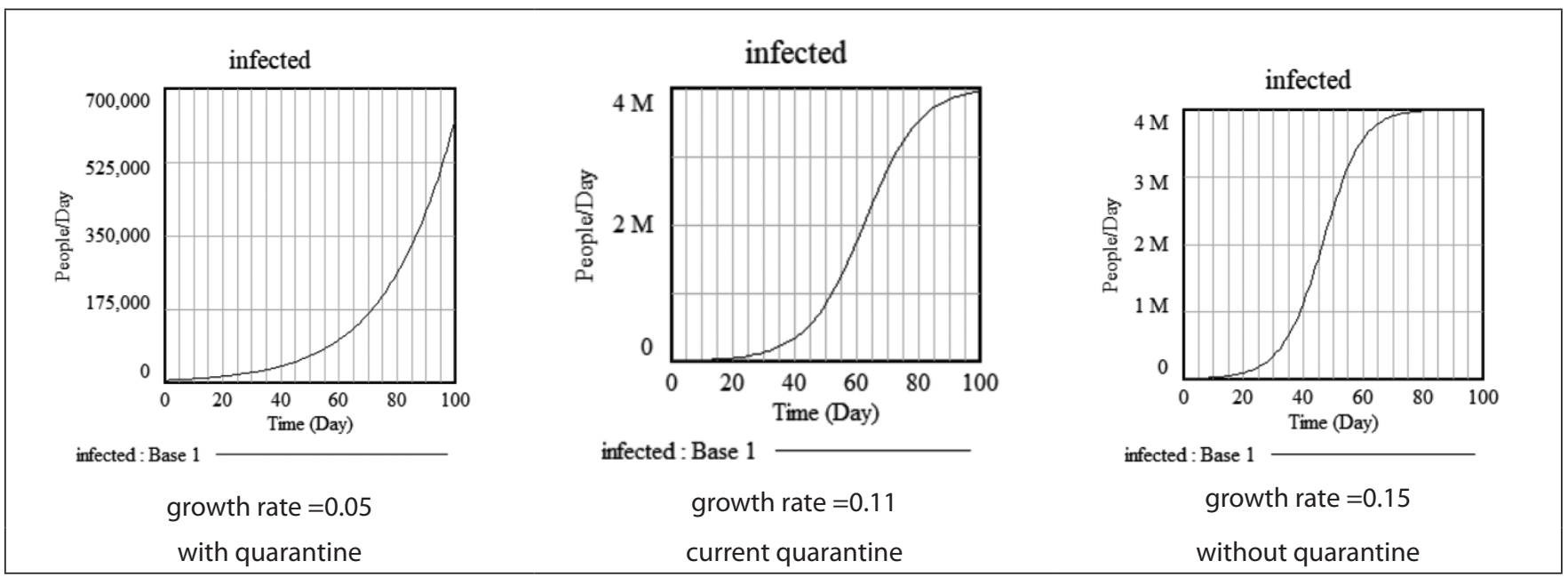

Fig. 4. The findings of the system dynamic model the number of infected from growing disease using Vensim

Table 2. The findings of alfa calculation using the Ordinary Least Square Methods

\begin{tabular}{ccccc}
\hline Variable & Coefficient & Std. Error & t-Statistic & Prob. \\
\hline Total population & 0.182586 & 0.089944 & 2.029987 & 0.0574 \\
\hline Industry capital input & 0.935019 & 0.067159 & 13.92243 & 0.0000 \\
\hline R-squared & 0.903628 & Mean dependent var & 25.31923 \\
\hline Adjusted R-squared & 0.898274 & S.D. dependent var & 0.543043 \\
\hline S.E. of regression & 0.173201 & Akaike info criterion & -0.574089 \\
\hline Sum squared resid & 0.539974 & Schwarz criterion & -0.474516 \\
\hline Log-likelihood & 7.740891 & Hannan-Quinn criteria. & -0.554651 \\
\hline Durbin-Watson stat & 0.359097 & & \\
\hline
\end{tabular}

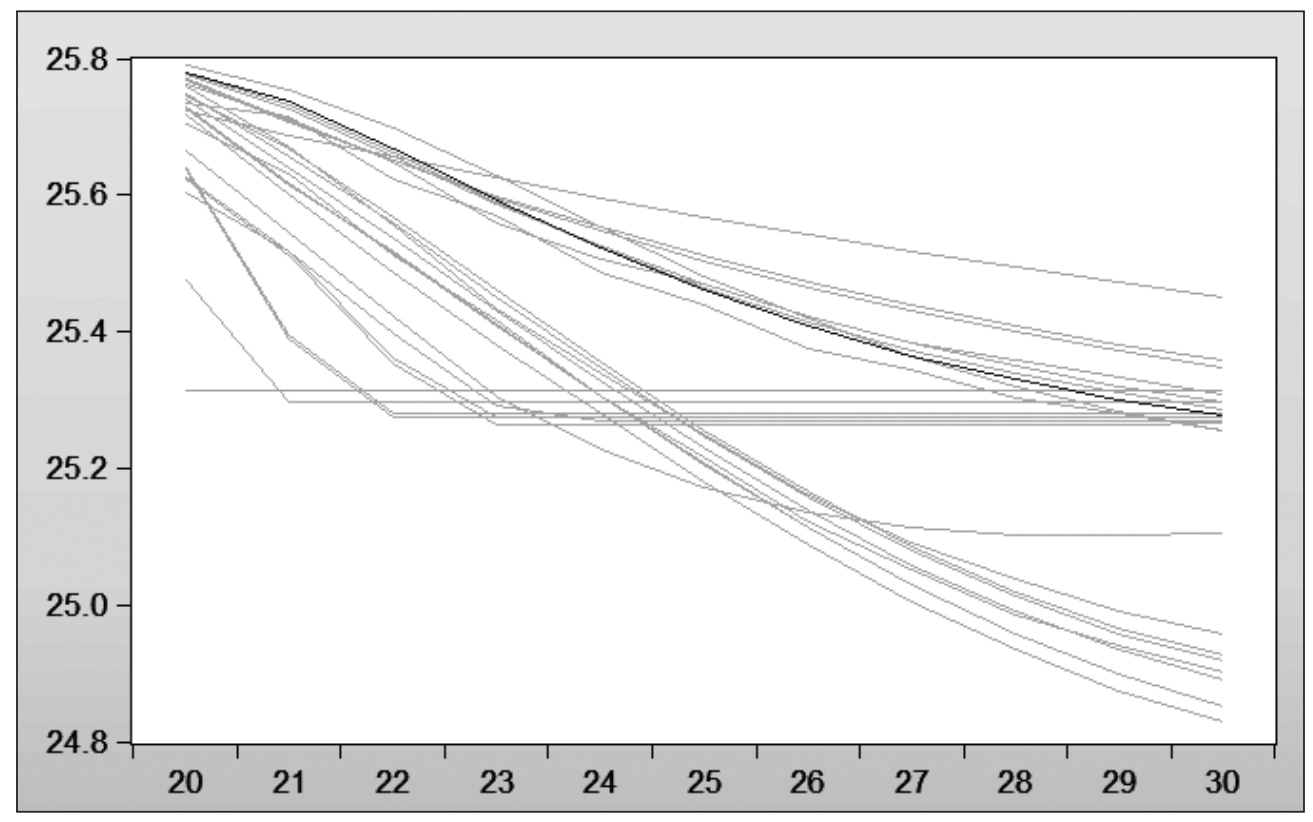

Fig. 5. The scenarios of GDP increment changes relate from the quarantine regime

analytical reviews have been published to forecast the COVID-19 pandemic consequences. In the paper [22] the scientists formalised the quarantine impact on the risk of medical system overloading and mortality due to COVID-19. The Institute of Mathematical Machines and
Systems Problems of the Ukraine National Academy of Science has developed a determinate SEIR model based on main medical parameters to predict the COVID-19 epidemic extent in Ukraine [23], the results of impact forecasting of social distancing individual scenarios on 
the COVID-19 spread are presented in the reports of the World Data Center "Geoinformatics and Sustainable Development" [24], the Institute for Economic Research and Policy Consulting [25].

Considering the OECD report [20] the adaptive quarantine due to COVID-19 has the significant impact on the national economic development. Thus, in the post-COVID-19 the inflation will be $8,7 \%$ as in preCOVID-19-5,5\%; exchange rate will be increased from 27 (pre-COVID-19) to 29.5 (post-COVID-19). Besides the experts predict the decreasing of GDP by $8 \%$ and salary from 12.5 to 10.7 thousand.

The findings of using Vensim after to input data and formulas could be presented as the graphs (Fig. 4). The data confirmed that the current rate of infected from growing disease was $11 \%$. In the government would continue quarantine the rate of infected from growing disease would be $15 \%$. If the quarantine cancelled the rate of infected from growing disease would be $5 \%$. The findings proved the government decisions on prolonging the quarantine regime was one of the effective ways to decline the negative consequences of the COVID-19.

For further calculation, the alfa of the formula (2) as defined by the Ordinary Least Square Methods using the EViews (Table 2).

The empirical results allowed concluding that the Total population and Industry capital input had a statistically significant impact on GDP increment. The coefficient of determination of the model was $90 \%$. Thus, alfa was accepted at the level 0,18.

With the purpose to develop the scenarios of GDP changes under the pandemic lockdown, the forecasting of GDP increment changes was analysed. Thus, the findings of using Vensim after to input data and formulas could be presented as the graph GDP increment (Fig. 5).

The empirical results proved that any types of quarantine regime lead to the declining of GDP increment. Besides, the highest decreasing would be if the government cancel the quarantine regime in Ukraine. Considering the data, the optimal scenario (red line on Fig. 5) - the quarantine would be prolonged.

\section{CONCLUSIONS}

The results of the bibliometric analysis showed the growing interest of the scientists to analyse of the pandemic issues. The scientists try to find effective ways to overcome the recession after the lockdowns due to COVID-19. The empirical results confirmed the hypothesis that lockdown has a negative impact on the economic, social, and ecological growth of the country. At the same time, in the case, if the government cancel the quarantine, the declining of GDP increment will be higher, than in scenario with quarantine. Moreover, the rate of infected from the growing disease will be the lowest if the quarantine will be continued (growth rate $-5 \%$ ). In this case, the government should provide the quarantine regime and strengthen the control of the compliance.

\section{REFERENCES}

1. Vladimir Rodríguez-Caballero C, Eduardo Vera-Valdés J. Long-lasting economic effects of pandemics: Evidence on growth and unemployment. Econometrics 2020;8(3):1-16. doi:10.3390/econometrics8030037

2. Loboda A, Smiyan 0, Popov S, Petrashenko V, Zaitsev I, Redko 0, Zahorodnii M, Kasyan S. Child health care system in Ukraine. Turk Pediatr Ars 2020; 55:S98-S104. doi:10.14744/TurkPediatriArs.2020.82997

3. Wang D, Hu B, Hu C, Zhu F, Liu X, Zhang J, Wang B, Xiang H, Cheng Z, Xiong Y, Zhao Y, LiY, Wang X, Peng Z. Clinical characteristics of 138 hospitalised patients with 2019 novel coronavirus-infected pneumonia in Wuhan, China. JAMA 2020;323(11):1061-9. doi:10.1001/jama.2020.1585

4. Anderson RM, Heesterbeek H, Klinkenberg D, Hollingsworth TD. How will country-based mitigation measures influence the course of the COVID-19 epidemic? Lancet 2020;395(10228):931-4. doi:10.1016/ S0140-6736(20)30567-5

5. Umar Z, Kenourgios D, Papathanasiou S. The static and dynamic connectedness of environmental, social, and governance investments: International evidence. Econ Model 2020;93:112-24. doi:10.1016/j. econmod.2020.08.007

6. Didenko I., Paucz-Olszewska J., Lyeonov S. et al. Social safety and behavioral aspects of populations financial inclusion: A multicountry analysis Journal of International Studies, 2020, 13(2), c. 347-359

7. Vasilyeva T., Lyeonov S., Lopa L. Forecasting Supply and Demand In the Regional Labor Market: In Search of Optimal Proportions of Financing Vocational Education Institutions In the Region. SocioEconomic Challenges. 2018; 2(1):69-84.

8. Vasilyeva, T., Bilan, S., Bagmet et al. Institutional development gap in the social sector: Crosscountry analysis Economics and Sociology, 2020, 13(1), c. 271-294.

9. Chygryn 0., Petrushenko Y., Vysochyna A. et al. Assessment of fiscal decentralization influence on social and economic development. Montenegrin Journal of Economics. 2018; 14(4):69-84.

10. Vorontsova, A., Vasylieva, T., Bilan, Y. et al. https://www.scopus.com/ authid/detail.uri?authorld=56644715400The influence of state regulation of education for achieving the sustainable development goals: Case study of Central and Eastern European countries Administratie si Management Public. 2020; (34): 6-26.

11. Bilan Y., Raišienè A.G.,Vasilyeva T. et al. Public Governance efficiency and macroeconomic stability: Examining convergence of social and political determinants. Public Policy and Administration. 2019; 18(2): 241-255.

12. Bilan, Y., Vasilyeva, T., Lyeonov, S. et al. Institutional complementarity for social and economic development. Business: Theory and Practice, 2019, 20, c. 103-115

13. Wang $Q$, Wang $S$. Preventing carbon emission retaliatory rebound postCOVID-19 requires expanding free trade and improving energy efficiency. Sci Total Environ 2020;746. doi:10.1016/j.scitotenv.2020.141158

14. Dogan, E., \& Inglesi-Lotz, R. The impact of economic structure to the environmental kuznets curve (EKC) hypothesis: Evidence from european countries. Environmental Science and Pollution Research 2020; 27(11): 12717-12724. doi:10.1007/s11356-020-07878-2

15. Bilan, Y., Streimikiene, D., Vasylieva, T., Lyulyov, O., Pimonenko, T., Pavlyk, A. Linking between renewable energy, $\mathrm{CO}$ emissions, and economic growth: Challenges for candidates and potential candidates for the E.U. membership. Sustainability 2019;11(6).11(6) doi:10.3390/su11061528

16. Vasylieva T, Lyulyov 0, Bilan Y, Streimikiene D. Sustainable economic development and greenhouse gas emissions: The dynamic impact of renewable energy consumption, GDP, and corruption. Energies 2019;12(17). doi:10.3390/en12173289 
17. Tonnang, E. Z., Greenfield, J., Mazzaferro, G., Austin, C. C. COVID-19 Emergency Public Health and Economic Measures Causal Loops: A Computable Framework." COVID-19 Emergency Public Health and Economic Measures Causal Loops: A Computable Framework (September 3, 2020), 2020: https://doi.org/10.15497/rda00049

18. Mehrjerdi, Yahia Zare, Ramin Alemzadeh, and Amir Hajimoradi. "Dynamic analysis of health-related factors with its impacts on economic growth." S.N. Applied Sciences 2.8 (2020): 1-17.

19. Xue, Y., Cheng, L., Wang, K., An, J., \& Guan, H. System Dynamics Analysis of the Relationship between Transit Metropolis Construction and Sustainable Development of Urban Transportation-Case Study of Nanchang City, China. Sustainability, 2020; 12(7): 3028.

20. The COVID-19 crisis in Ukraine. Available at: https://www.oecd.org/ eurasia/competitiveness-programme/eastern-partners/COVID-19CRISIS-IN-UKRAINE.pdf

21. World Bank. Available at: https://www.worldbank.org

22. Ferguson, Neil, et al. Report 9: Impact of non-pharmaceutical interventions (NPIs) to reduce COVID19 mortality and healthcare demand. Imperial College London, 2020, 10: 77482.

23. The forecast of pandemic in Ukraine. Available at: http://www.nas.gov. ua/EN/Messages/Pages/View.aspx?MessagelD=6346

24. Foresight of COVID-19. Available at: http://wdc.org.ua/uk/covid19project

25. Post-COVID 19: scenarios of economic recovering. Available at: https://rpr.org.ua/news/pislia-covid-19-stsenarii-ekonomichnohovidnovlennia/

\section{Funding:}

The research was funded by the grant from the National Research Foundation of Ukraine "Economic and mathematical modelling and forecasting of the COVID-19 influence on Ukraine development in national and regional contexts: public health factors and socio-economic and ecological determinants» ID 2020.01/0181).

\section{Authors' contributions:}

According to the order of the Authorship

\section{ORCID}

Vladyslav A. Smiianov: 0000-0002-4240-5968 ${ }^{A, E, F}$

Oleksii V. Lyulyov: 0000-0002-4865-7306 ${ }^{B, D, F}$

Tetyana V. Pimonenko: 0000-0001-6442-3684 B,C,F

Tetyana A. Andrushchenko: 0000-0003-2858-8267 E,F

Serhii G. Sova: 0000-0002-6833-3149 ${ }^{B, F}$

Natalia V. Grechkovskaya: 0000-0001-6497-2149 E,F

\section{Conflict of interest:}

The Authors declare no conflict of interest

\section{CORRESPONDING AUTHOR}

\section{Oleksii V. Lyulyov}

Sumy State University

2, Rymskogo-Korsakova st., 40007 Sumy, Ukraine

tel: +380667905720

e-mail:alex_lyulev@econ.sumdu.edu.ua

Received: 31.08 .2020

Accepted: 29.10 .2020
A - Work concept and design, B - Data collection and analysis, C - Responsibility for statistical analysis,

D-Writing the article, $\mathbf{E}$-Critical review, $\mathbf{F}$ - Final approval of the article 